\title{
Monitoring techniques: "StegoGIS: a geographical information system for knowing and preventing infestation risks in cultural heritage"
}

\begin{abstract}
Since 2004, the Cicrp: "Centre Interrégional de Conservation et Restauration du Patrimoine", located in Marseilles has been involved in an interdisciplinary research program dealing with infestation and re-infestation, on lining pastes used in painting conservation, by the Stegobium paniceum through a GIS system : a geographical information system called "StegoGIS". The GIS helps understand the insects ethology in its environmental context, mainly in flour and semolina millings in order to determine analysis criteria to prevent, mitigate and fight infestation in the cultural property environment. Our approach is based on three main lines:

1- A transverse approach of infestation in any type of cultural heritage institution: archives, libraries, museums, historic buildings where organic material collections and environment are attractive on an "insect point of view".

2 -An IPM strategy (Integrated Pest Management) including conservation and management of collections and buildings also based on an infestation survey with actual or potential risks.

3- A "decision- making tool" in diagnosis, preventing methods and treatments for professional conservation staff.
\end{abstract}

Key words: cartography, IPM (Integrated Pest Management), insects.

\section{INTRODUCTION}

Since 1990, Marseilles museums have been facing a huge infestation problem. This phenomenon has been studied and surveyed from the 90's and carried on a research program in 2004 at the Cicrp (Baslé et al., 2009). The infestation was found on more than one hundred paintings, mainly found in the Art Museum of Marseilles. Well known and high degradations were noted, exceeding the usual signs of woodworm exit holes (Fig. 1).

The first target consisted in identifying the insect and determining the reasons for its activity. The insect was the Stegobium paniceum (Kashef, 1955; Delobel \& Tran, 1993; Delvare \& Aberlenc, 1989; Fabre, 1979; Favral \& D’Aguilar, 2004) (Fig. 2) particularly attracted by the starch paste cooked with flour and commonly used in relining techniques (Bouillon \& Fohrer, 2008). 


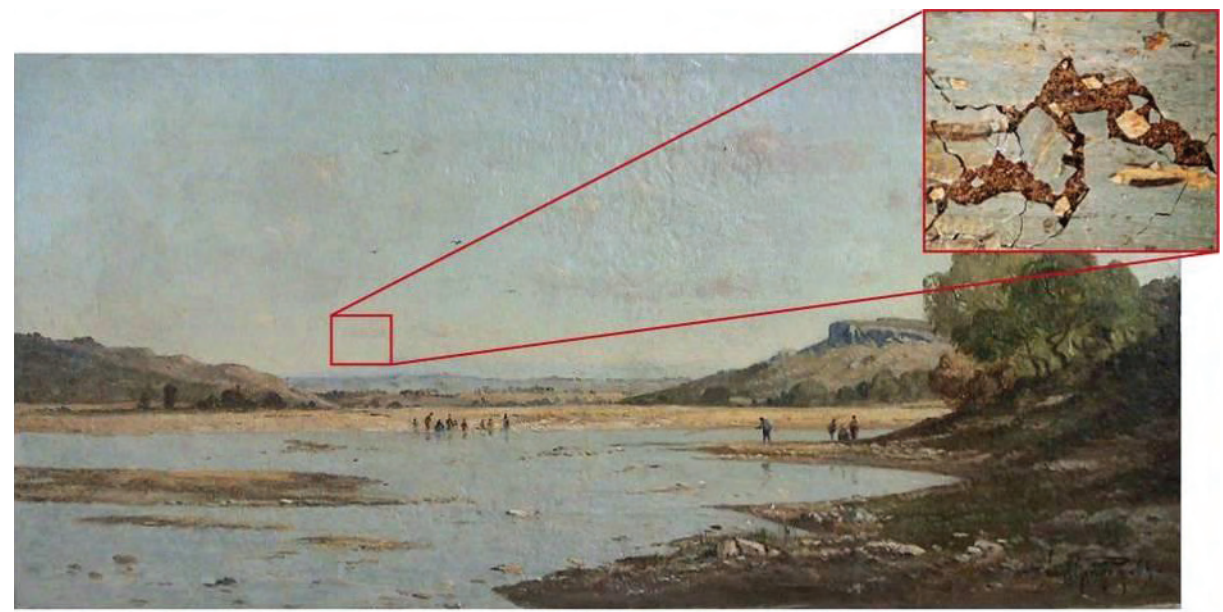

Pins au bord de la Durance - Paul Guigou, 1869 - $N^{\circ}$ d'inventaire : BA B98 - Musée de Beaux-Arts de Marseille.

Fig. 1- Alteration on the painting media and lining support.

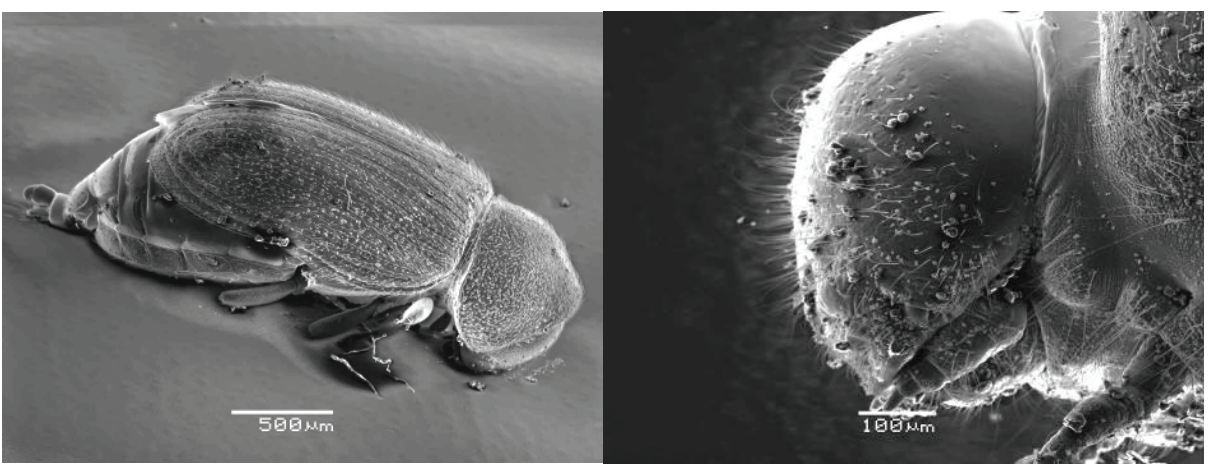

Fig. 2 - Stegobium paniceum adult (left) and larva (right); pictures taken from a Scanning Electronic Microscope JEOL 6460 LV, (F. Daniel, IRAMAT-CRP2A, Université de Bordeaux 3-Michel de Montaigne). 
Working from the archives of the Art Museum resulted in valuable data: the infested artefacts had been relined in Marseilles from 1977 to 1986 by a conservator using glue-paste adhesives combining animal and flour glues (traditional Latina method documented since 1660).

Through painting survey, it appeared that degradations were followed by a problem of re- infestation of the paintings which had been disinfested in 1993. A major infestation occurred, not only in the panel of the relined paintings but also on other paintings: we were facing a generalized and permanent infestation (Fohrer \& Baslé, 2005a; Fohrer \& Baslé, 2005b; Fohrer \& Baslé, 2006; Fohrer et al., 2006b).

Finally, the survey showed that visual examination was not a sufficient criteron to discover an infested or potentially infested state. In fact, the active character of this infestation was difficult to be determined. Recognizing or identifying insect pests could be done through common signs of insect activity such as fresh frass (debris of food fragments or dry excreta) from woodworm exit holes or presence of insects adults (dead or alive) but several artefacts didn't show any of these visible signs and, later, showed an infestation.

These specific criteria of Stegobium paniceum's infestation led the Cicrp to develop working processes related to the knowledge of the insect life cycle (Paulian, 1988), conditions of reproduction and proliferation (Fohrer et al., 2006a). It also led us to accurately analyse the various glue-paste adhesives components according to different countries' recipes: coletta in Italy, fish adhesive in Russia etc.. All these approaches led to think about a preventive strategy. Among the different assistance tools, we decided to choose a surveying cartography tool: a GIS (Geographical Information System) that we called "StegoGIS".

\section{MATHERIALS AND METHODS}

Definition and principles of the GIS tool:

What is a GIS?

A Geographical Information System is a computerized tool to represent and analyse some localized data from a geographical point of view which contribute to environmental management.

GIS offers opportunities for all kinds of data bases, such as query and statistical analysis, through a unique visualization of geographical maps. Otherwise, and because of this specific capability, GIS is a unique tool, accessible to a large audience and applying to a wide variety of applications.

A GIS deals with five functions:

- Geographical data: digital data capture (data acquisition)

- Database management (archive storage)

- Geographical data processing (analysis)

- Visualization (display)

- Graphic representation (abstraction)

A GIS should reply to five questions: 
-Where? Localization of the study field and definition of its geographical extent -What? Definition of the objects which can be represented in the geographical space -How? Distribution of these objects and their relations between them (space analysis) -When? Object or event description (time analysis)?

-And then? What would happen if such event occurred?

A GIS is intended to structure the geographical information data which appear as "stackable" layers.

StegoGIS

GIS helps us to understand the ethology of the Stegobium paniceum and other insects, in their environmental context, found in flour and semolina millings. The method was adapted to the cultural property environment.

Our approach is based on three main lines:

1- Artefacts potential or actual infestation survey, artefacts being able to move from inside the building to the outside, in case of exhibits for instance, or artefacts moving from the outside to the inside in case of restoration or acquisition, or after building renovation...

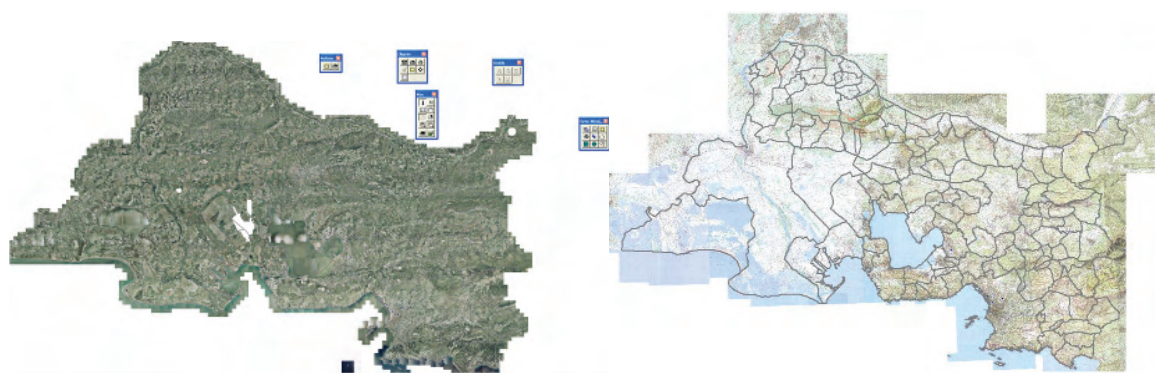

Fig. 3 - « Bouches du Rhône» map IGN BD ortho (left) and map IGN Scan 25 (right).

2- Recognising pests and assessing the problem by inspection, looking for insects activities like woodworm exit holes on paintings.

3- Stegobium paniceum and other insect trapping survey inside the geo referenced places.

\section{MATERIALS}

The StegoGIS has been developed from map info 7.5 related to a Microsoft access data base. We used airplane ortho-photos provided by the IGN (national geographic institute, BD ortho) and scanned images (IGN Scan 25) (Fig. 3). In order to process the working data, we chose a cartography raster (scale: 25/1000). The investigation was made in Marseilles where there are several flour and semolina mills (4 mills) and collections too (13 museums, 2 places for archive collections, and several historic buildings and libraries) but the tool can be extended to a regional or national area. 


\section{RESULTS}

\section{Data and analysis}

Data were first collected in flour mills and then the experience was extended to the

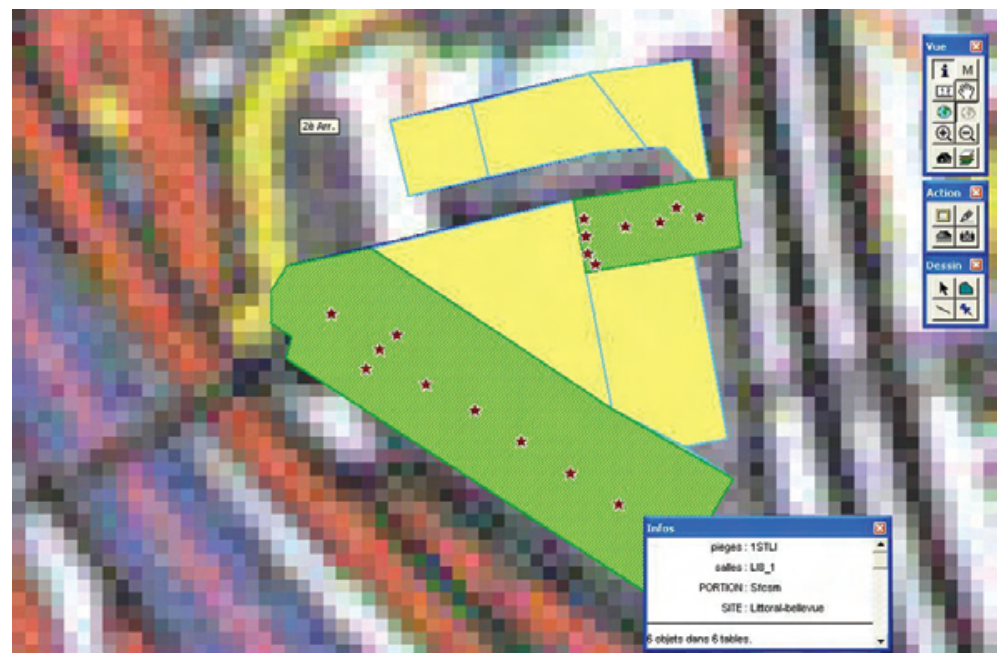

Fig. 4 - Trap localization.

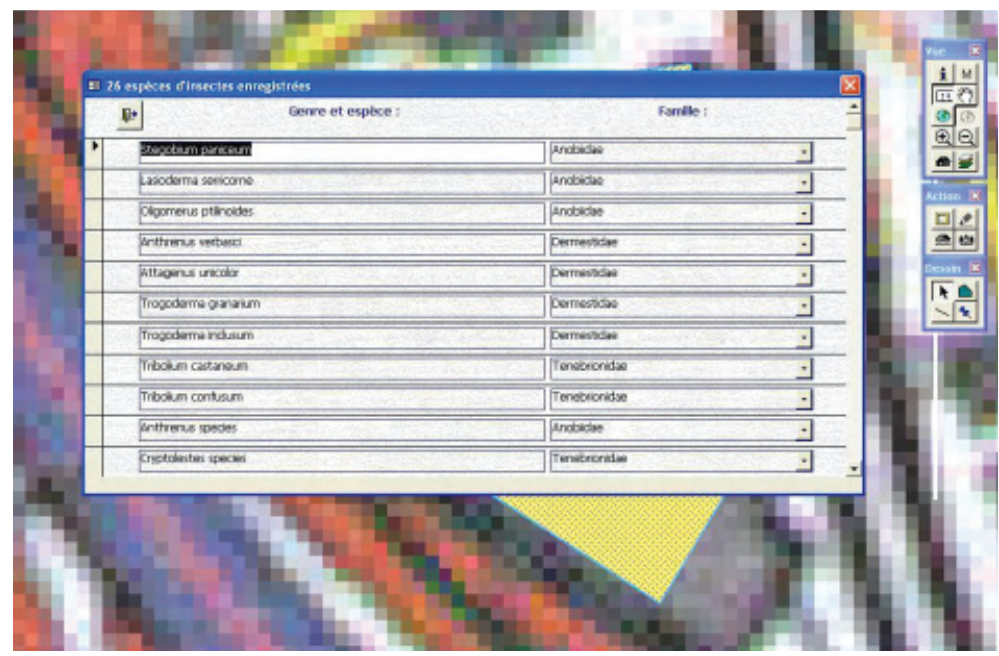

Fig. 5 - Insect identification: family-genus-species. 


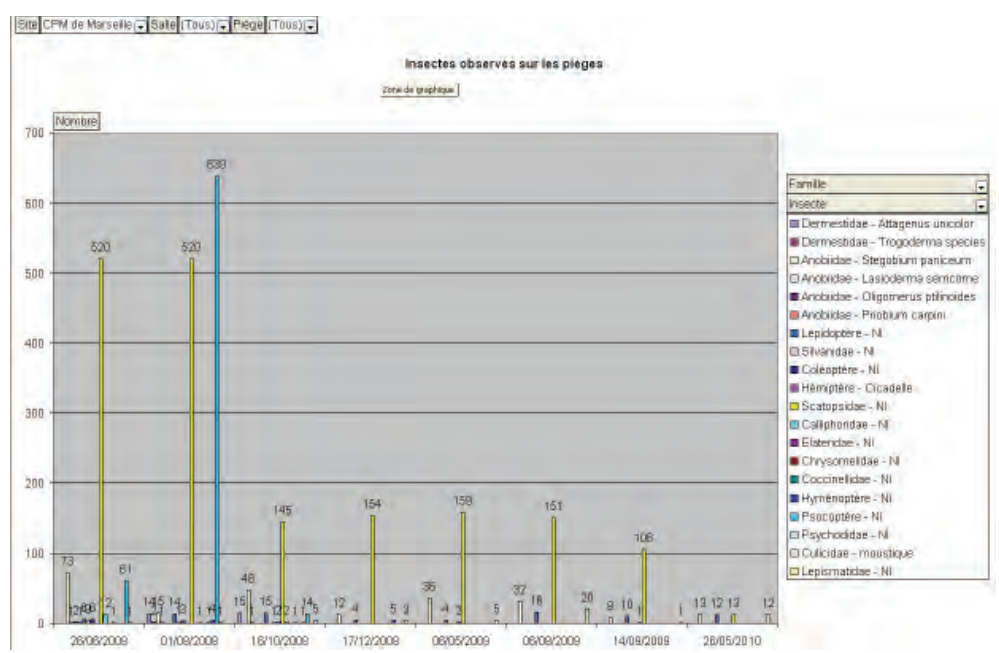

Fig. 6 - Insect identification in Marseilles museum storage area.

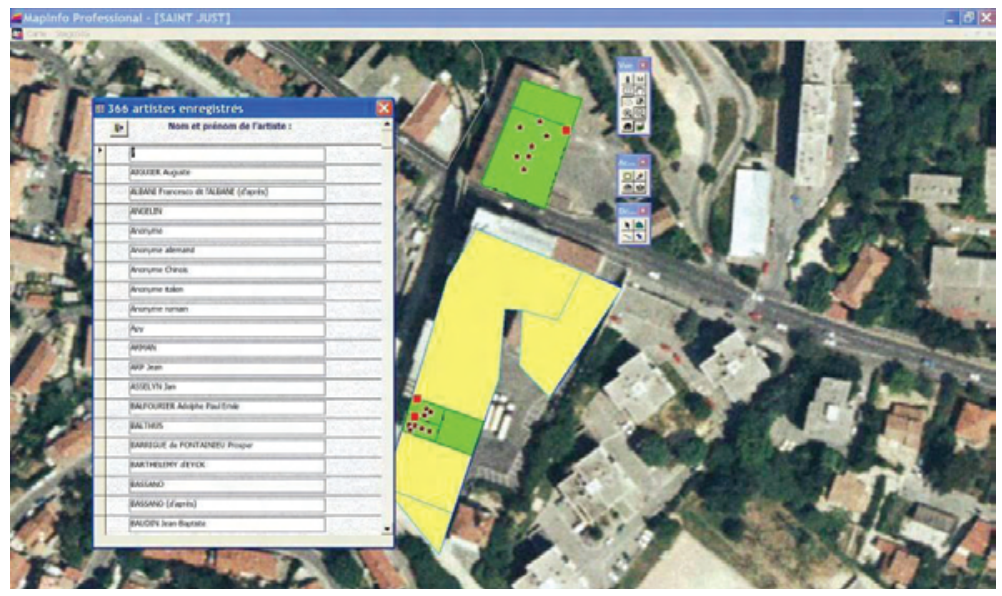

Fig. 7 - Artists list, traps (stars) and painting localization (red squares).

cultural heritage, based on the same approach concerning insects but of course different concerning the relevant information.

The data are collected through the installation of ultra violet (UV) traps (Fig. 4) with sticky boards and specific pheromones traps in order to record insects caught from traps (materials : date-label traps, brand traps) and characteristics. As for insects: identification, number, and classification according to the "Linnaeus's» (Figs 5 and 6). Traps 
are located with accuracy in the GIS. We also record data on environmental conditions (relative humidity and temperature), of interest regarding the insect cycle and presence. Suspended UV (ultra violet) traps were used both for monitoring and mitigation and gave us satisfactory results.

In order to get the best results for trapping, it should be noted that the trap location is determined for maintenance reasons (changing UV tubes for which life is limited: from 6000 to 9000 hours). The best is to change them each, once a year, according mainly to UV tubes cost which has to be multiplied by the number of traps. We chose UV traps with a maximum of health and safety requirements: standard anti explosion, water repellent, certified ATEX dusts zone 22. The size of one trap was 690 x 205 x 400mm with four $20 \mathrm{~W} / 5$ tubes and a potential attraction of 350 square meters.

Disinsectisation treatments history was also integrated (type of treatment and date of application) in flour and semolina millings and cultural heritage places.

This historical aspect is very useful especially for the IPM (Insect Pest Management) in order to follow the re-infestation risks and also to establish a "decision-making tool" for people in charge of the collections, according to the treatment repeatability and according to the location of the infestation (generalized or partial). It is also valuable as a memory tool in relation to the "turn over" of the people in charge of the institutions.

For cultural objects, different data are stored: information concerning the artefact itself (painter, date, techniques) (Fig. 7). We also record information concerning the restoration and the conservators who have been working on paintings. Conservation memory of the different operations from insects treatments to painting conservation is of high importance regarding the artefact's history.
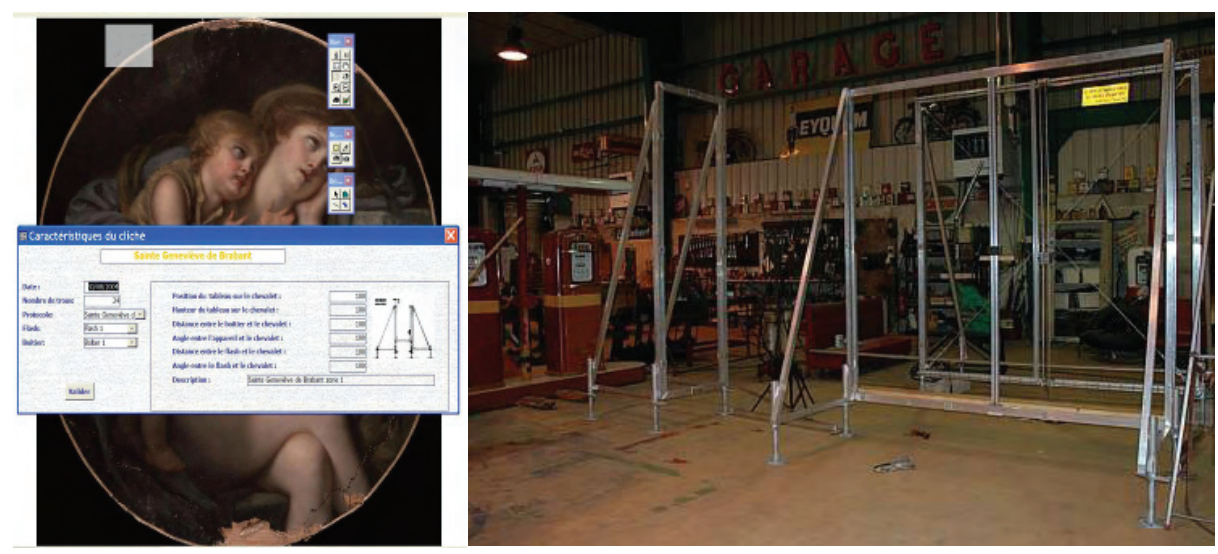

Fig. 8 - Structure and protocol. 


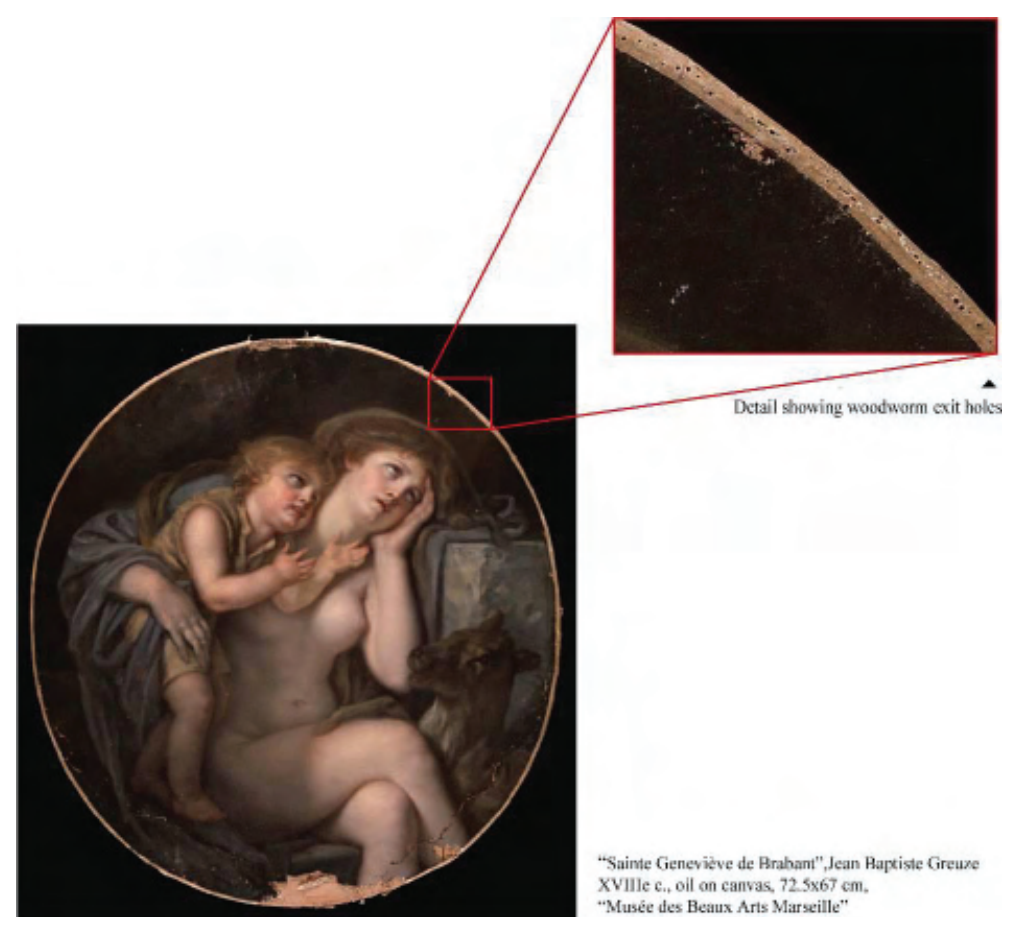

Fig. 9 - Image analysis: descriptive method (Picture F. Baussan \& P. Glotain, cicrp).

\section{Image analysis}

First we had to figure out a new structure to take pictures and a relevant protocol to reproduce pictures in the same conditions at different times (Fig. 8).

Then we developed an "observation tool" through comparative image analysis. This "woodworm exit holes counting system" is based on a statistical comparing pictures protocol. This system provides us with a reproducible tool (Figs 9 and 10).

\section{DISCUSSION AND CONCLUSION}

We started the GIS in 2004, recording the data in the flour milling in Marseilles then we added the semolina milling data in Vitrolles and stopped to record the environmental data in 2010 in this field.

It helped for a better understanding of the evolution in a general context according to insect pests which are present all around us in our everyday lives and can have effects on the cultural heritage present in the same areas. It was also useful for people in charge of the food processing industry and helped them to get better assessment of the infestation causes that are constantly faced. 


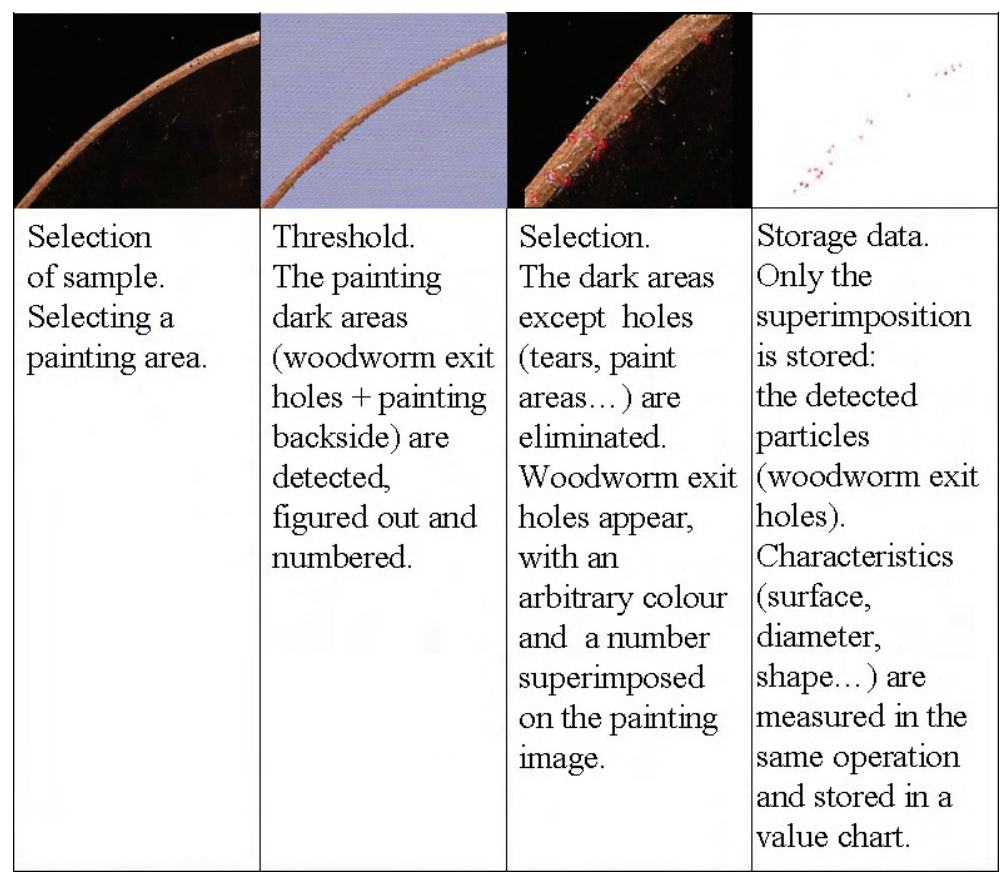

Fig. 10 - Image analysis system summary.

According to the cultural heritage, the GIS application makes slower progress for different reasons. First of all these people are not familiar with GIS systems: these tools are commonly used by the archaeologists but not by the curators and conservators (question of training and references). But, as time goes on and when compared to our beginnings, things are getting better. These two worlds are completely different: food processing industry and cultural heritage field especially concerning the notion of time and the way the insect pests are dealt. Meanwhile we learned a lot from each other and even if our purpose wasn't to borrow their technology to apply it to our field, we appreciate their organization and their abilities to face insect pests. We learned a lot on the methodological point of view. We also exchanged a lot of data with the pest exterminators people dealing, every day, with all kinds of pests.

GIS is also a valuable tool for biologists, especially the entomologists, to store all the useful data.

GIS is a complex tool needing a suitable maintenance as far as computer and software systems are concerned. Today we can get the maps information through Google map which wasn't possible at the time we started to work. As we develop the StegoGIS we extend the experimentation in the cultural heritage media through an extranet col- 
laborative portal server: http://stegobium.cicrp.fr. The collaborative portal server intends to centralize the information and consolidates the data.

In 2011 and 2012 a "national cartography survey in the French cultural heritage" (museums, archives, libraries and historic buildings) for a better knowledge of infestation risks and reality in the cultural heritage on our territory will be developed.

\section{ACKNOWLEDGEMENTS}

We would like to thank the people of the food processing industry as M. Mario Cameli, Mrs Elisabeth Martin, and M. René Devot, who let us investigate and collect data in our quest of a better understanding the insect pests phenomena. We would also like to thank the people of the extermination field; especially M. Didier Jehanno and M. Jean François Delbonnel who gave us a lot of information concerning IPM and treatments in mills. We would like to thank the University of Perpignan and especially the IUT of Carcassonne and the people who helped us, in providing their knowledge and their competences: M. Jean Pierre Sorribas, M. Pierre Wolsztynski and all the team. Related to the collaborative server we would like to thank Apem society end especially M. Laurent Plainecassagne and M. Thomas Portier, with them, we will keep going on the project of the national cartography survey.

\section{REFERENCES}

Baslé K., Bouillon N., Fohrer F., Guillon O., May R., 2009 - Pour une approche raisonnée des problématiques d'infestation en milieu patrimonial: le cas du Stegobium paniceum, Techné, 29: 109-114.

Bouillon N., Fohrer F., 2008 - Study of pest infestation of glue paste lined easel paintings: a characterization of traditional glue paste recipes and their relevant volatils organic compounds by chromatography/mass Spectrometry raster. Icom-CC $5^{\text {th }}$ Triennial Meeting, New Delhi, 22-26 September 2008. Poster.

Delobel A., Tran M., 1993 - Les coléoptères des denrées alimentaires entreposées dans les régions chaudes, Faune tropicale XXXII, Paris, Orstom / CTA, 1993.

Delvare G., Aberlenc H.P., 1989 - Les insectes d'Afrique et d'Amérique tropicale: clés pour la reconnaissance des familles, CIRAD, département GERDAT, laboratoire de faunistique, 170-200.

FABRE J.H., 1979 - Souvenirs Entomologiques: étude sur l'instinct et les mœurs des insectes (10 séries), Delagrave Editeurs 1921, réédition 1979.

Favral A., D'Aguilar J., 2004 - Glossaire entomologique, Delachaux et Niestlé.

FoHrer F., BASLÉ K., 2005a - Le Stegobium paniceum: un amateur d'art indélicat (1ère partie). NPI (nuisibles et parasites information), 41: 24-25.

Fohrer F., BASlé K., 2005b - Le Stegobium paniceum: un amateur d'art indélicat (2ère partie). NPI (nuisibles et parasites information), 42: 20.

Fohrer F., BASLÉ K., 2006 - Un amateur d'art démasqué. NPI (nuisibles et parasites information), 49: 31-33.

Fohrer F., Baslé K., Daniel F., 2006a - Problématique de l'infestation des colles de rentoilage des peintures de chevalet par le Stegobium paniceum (L.). Support tracé N ${ }^{\circ}$ 6, 78-85. 
Fohrer F., Baslé K., Daniel F., 2006b - L'affaire Stegobium: Mémogravure numéro 001. Portefeuille pédagogique, 1-35.

Kashef A., H., 1995 - Etude biologique du Stegobium paniceum L. (Col. Anobiidae) et de son parasite Lariophagus distinguendus Först. (Hym. Pteromalidae). Annales de la Société Entomologique de France, 124: 1-88.

Paulian R., 1988 - Biologie des coléoptères, Lechevalier ed.

Katia BasLé, CICRP, 21 rue Guibal 13003 Marseille, France.

E-mail:katia.basle@cicrp.fr

Odile Guillon, CICRP, 21 rue Guibal 13003 Marseille, France.

E-mail: odile.guillon@cicrp.fr

FABIEN FoHRER, CICRP, 21 rue Guibal 13003 Marseille, France.

E-mail: fabien.fohrer@cicrp.fr

FLORÉAL DANIEL, Institut de recherche sur les Archéomatériaux, UMR CNRS 5060, Centre de Recherche en Physique Appliquée à l'Archéologie (CRPAA), Université Bordeaux 3, Domaine Universitaire - Maison de l'archéologie, Esplanade des Antilles, 33607 Pessac, France.

E-mail: fdaniel@u-bordeaux3.fr 